\title{
Endoscopic third ventriculostomy for hydrocephalus associated with tectal gliomas
}

\author{
Khan W. Li, M.D., Chanland Roonprapunt, M.D., Ph.D., Herman C. Lawson, M.D., \\ I. Rick Abbott, M.D., JefFrey Wisoff, M.D., Fred Epstein, M.D., \\ AND GEORGE I. JaLlo, M.D.
}

Department of Neurosurgery, Johns Hopkins University, Baltimore, Maryland; Department of Neurosurgery, Albert Einstein School of Medicine, New York; and Department of Neurosurgery, New York University Medical Center, New York, New York

\begin{abstract}
Object. Tectal gliomas are a distinct form of pediatric brainstem tumor that present in patients with symptoms related to increased intracranial pressure due to obstructive hydrocephalus. The natural history of these lesions is often uniquely indolent. Thus, initial surgical therapies are directed at treatment of hydrocephalus, usually with ventricular shunt placement. Recently, third ventriculostomy has been used in patients with tectal gliomas, both as an initial procedure and after shunt failures. In this report the authors review their experience with the treatment of hydrocephalus in patients with tectal gliomas.

Methods. The authors reviewed 31 consecutive cases of tectal gliomas and compared the success rates of ventricular shunt placement with the success rates of endoscopic third ventriculostomy (ETV). Shunt placement procedures were associated with a significant number of malfunctions, and most patients required shunt revisions. The ETV procedure was attempted both as an initial treatment and after shunt malfunction. Overall, ETV was attempted in 18 patients and was performed successfully in all cases. At the time of follow-up evaluation, 16 patients (89\%) were shunt free.

Conclusions. The authors found that ETV could be performed with good long-term success both as an initial treatment and after shunt failure. Overall, ETV was found to be superior to ventricular shunt placement in the management of hydrocephalus associated with tectal gliomas.
\end{abstract}

\section{KEY Words - tectal glioma - endoscopic third ventriculostomy - aqueductal stenosis • hydrocephalus - tectal plate $\bullet$ astrocytoma $\bullet$ children}

Tectal gliomas are uncommon tumors that arise from the collicular plate near the sylvian aqueduct. The clinical presentation is most often related to symptoms of obstructive hydrocephalus due to compression of the cerebral aqueduct. ${ }^{15}$ Diagnostic CT scans reliably demonstrate triventricular hydrocephalus and may also reveal calcification and postcontrast enhancement in the region of the tectal plate. $5,13,16$ The diagnosis of tectal glioma, however, is best made based on MR imaging studies, which usually demonstrate a $\mathrm{T}_{1}$-weighted hypo- to isointense, $\mathrm{T}_{2}$-weighted hyperintense lesion within the tectal plate that may or may not enhance after administration of contrast material. ${ }^{5}$

The natural history of these tumors is most often indolent; ${ }^{6,17}$ thus, treatment of hydrocephalus is often the only surgical procedure that most patients require. Traditionally, CSF diversion has been accomplished with shunt procedures. Nevertheless, because of the failure rates and complications associated with ventricular shunt placement, other methods of CSF diversion have been investigated recently. Theoretically, ETV provides a more physiological solution to the problem of obstructive hydrocephalus and

\footnotetext{
Abbreviations used in this paper: $\mathrm{CSF}=$ cerebrospinal fluid; $\mathrm{CT}=$ computerized tomography; ETV = endoscopic third ventriculostomy; MR = magnetic resonance; $\mathrm{VP}=$ ventriculoperitoneal.
}

may be performed with low morbidity and high shunt-free success rates. ${ }^{10}$ The success of ETV in the treatment of tectal gliomas has, however, never been directly compared with that of ventricular shunt placement. To assess whether ETV or ventricular shunt placement was superior in managing hydrocephalus, we reviewed our series of 31 consecutive patients with tectal gliomas.

\section{CLINICAL MATERIAL AND METHODS}

\section{Patient Population}

Thirty-one patients with tectal gliomas were identified from a database of those with intracranial tumors who had been treated surgically by the authors between 1970 and 2002. A comprehensive review of medical charts, pertinent radiographic data, and operative reports was conducted. The mean age of the patients at the time of the first intervention was 11 years (range 6 weeks-20 years). There was an equal proportion of males (16) and females (15). Followup data were obtained from clinic visits and/or telephone interviews with patients and primary care physicians. The surgical technique for performing third ventriculostomy has been described previously. ${ }^{12}$ All attempted ETVs were performed successfully, with no intraoperative complications. 
K. W. Li, et al.

Externalized drains were not used postoperatively. Ventricular shunts, primarily VP devices, were inserted in the standard fashion.

\section{RESULTS}

\section{Clinical Presentation}

The most common presenting symptoms were related to increased intracranial pressure: headache $(65 \%)$, nausea/ vomiting (35\%), and lethargy (32\%). Other symptoms and signs included ataxia and incoordination (32\%), and visual changes including Parinaud syndrome and papilledema $(30 \%)$. Interestingly, two patients $(6.5 \%)$ presented after episodes of minor head trauma. The median time to follow-up evaluation was 8 years.

\section{Neuroimaging Studies}

All patients demonstrated evidence of obstructive hydrocephalus at the level of the sylvian aqueduct on imaging studies. Eight patients (26\%) had evidence of postcontrast tumor enhancement on CT or MR imaging studies. Of these eight patients, five (62\%) presented initially with contrast enhancement, whereas three (38\%) demonstrated new enhancement several years after their initial presentation, along with evidence of tumor progression.

\section{Treatment of Hydrocephalus}

Demographic and clinical data for all patients are reported in Table 1. All patients underwent CSF diversion procedures; VP shunt placement was performed as the initial treatment in 23 cases (74\%), whereas ETV was performed in the remaining eight (26\%). Among the 23 patients who underwent shunt placement, $18(78 \%)$ required additional procedures (shunt revision, ETV, or both), for a success rate of $22 \%$. Ten of these 18 patients subsequently underwent ETV.

Of the eight patients who underwent ETV initially, only one required an additional procedure for treatment of hydrocephalus, for an initial success rate of $88 \%$. The remaining patient underwent revision ETV 1 year after the initial procedure and has not required any further interventions. For the 10 patients who initially underwent shunt placement but later had ETV, the success rate was slightly lower, at $70 \%$ (seven of 10). The initial success rate of ETV was $78 \%$ (14 of 18) and the overall proportion of shunt-free patients was $16(89 \%)$ of 18 at the time of follow-up review.

Patients who initially received shunts underwent a total of 110 additional CSF diversionary procedures during the study period, or 0.5 procedures per patient per year. In contrast, patients who were treated initially with ETV underwent an additional procedure only once in 34 patient-years (approximately 0.03 procedures/patient-year).

\section{ILLUSTRATIVE CASE}

This 8-year-old boy presented at the emergency room with a 4- to 6-week history of intermittent vomiting, headaches, and diplopia. He had occasional episodes of ataxia secondary to his double vision. Neurological examination demonstrated a sixth cranial nerve palsy and papilledema. His visual acuity was 20/25 in the right eye and 20/40 in the
TABLE 1

Clinical data in 31 patients with hydrocephalus due to tectal glioma who were treated with either shunt placement or ETV*

\begin{tabular}{|c|c|c|c|c|c|}
\hline Case No. & $\begin{array}{l}\text { Age (yrs), } \\
\text { Sex }\end{array}$ & 1st Procedure & $\begin{array}{l}\text { No. of } \\
\text { Shunts }\end{array}$ & $\begin{array}{l}\text { No. of } \\
\text { ETVs }\end{array}$ & $\begin{array}{l}\text { Shunt Free } \\
\text { Post-ETV }\end{array}$ \\
\hline 1 & $16, \mathrm{M}$ & shunt & 2 & 2 & yes \\
\hline 2 & $9, \mathrm{M}$ & shunt & 2 & 0 & NA \\
\hline 3 & $16, \mathrm{~F}$ & shunt & 1 & 1 & yes \\
\hline 4 & $10, \mathrm{M}$ & shunt & 3 & 0 & NA \\
\hline 5 & $3, \mathrm{~F}$ & ETV & 0 & 1 & yes \\
\hline 6 & $9, \mathrm{~F}$ & shunt & 5 & 0 & NA \\
\hline 7 & $11, \mathrm{~F}$ & shunt & 1 & 0 & NA \\
\hline 8 & $17, \mathrm{M}$ & ETV & 0 & 1 & yes \\
\hline 9 & $20, \mathrm{~F}$ & shunt & 2 & 1 & yes \\
\hline 10 & $8, \mathrm{~F}$ & shunt & 3 & 0 & NA \\
\hline 11 & 7, F & shunt & 2 & 0 & NA \\
\hline 12 & $0.12, \mathrm{~F}$ & shunt & 2 & 0 & NA \\
\hline 13 & $2, \mathrm{M}$ & shunt & 2 & 1 & yes \\
\hline 14 & $19, \mathrm{M}$ & shunt & 2 & 2 & no \\
\hline 15 & $13, \mathrm{~F}$ & shunt & 43 & 1 & no \\
\hline 16 & $7, \mathrm{~F}$ & ETV & 0 & 2 & yes \\
\hline 17 & $15, \mathrm{M}$ & ETV & 0 & 1 & yes \\
\hline 18 & $8, \mathrm{M}$ & shunt & 10 & 1 & yes \\
\hline 19 & $14, \mathrm{M}$ & ETV & 0 & 1 & yes \\
\hline 20 & $12, \mathrm{M}$ & shunt & 2 & 0 & NA \\
\hline 21 & $5, \mathrm{M}$ & shunt & 3 & 0 & NA \\
\hline 22 & $10, \mathrm{~F}$ & shunt & 5 & 1 & yes \\
\hline 23 & $12, \mathrm{M}$ & ETV & 0 & 1 & yes \\
\hline 24 & $13, \mathrm{~F}$ & shunt & 1 & 0 & NA \\
\hline 25 & $20, \mathrm{~F}$ & shunt & 1 & 0 & NA \\
\hline 26 & $6, \mathrm{~F}$ & shunt & 1 & 0 & NA \\
\hline 27 & $18, \mathrm{M}$ & ETV & 0 & 1 & yes \\
\hline 28 & $8, \mathrm{M}$ & ETV & 0 & 1 & yes \\
\hline 29 & $15, \mathrm{M}$ & shunt & 1 & 0 & NA \\
\hline 30 & $13, \mathrm{~F}$ & shunt & 2 & 1 & yes \\
\hline 31 & $15, \mathrm{M}$ & shunt & 1 & 1 & yes \\
\hline
\end{tabular}

$* \mathrm{NA}=$ not applicable.

left. The remainder of his examination yielded normal results. A CT scan demonstrated triventricular hydrocephalus with transependymal edema (Fig. 1). An MR image with and without addition of contrast material confirmed the obstructive hydrocephalus and a nonenhancing tumor of the tectal region (Fig. 2). The patient underwent an ETV and experienced immediate resolution of his headaches. At the 6-month follow-up visit he was asymptomatic, with dramatic improvement of his papilledema and diplopia. An MR image demonstrated resolution of the transependymal edema and a decrease in ventricular size (Fig. 3).

\section{DISCUSSION}

Brainstem gliomas are a common form of pediatric brain tumor. The tectal glioma is a unique subset of brainstem gliomas. These tumors often present in patients with lateonset obstructive hydrocephalus that can be confused with benign aqueductal stenosis. ${ }^{3}$ Tectal gliomas are believed to be low-grade astrocytic tumors that usually follow a benign clinical course. . $^{13,18}$

Treatment of hydrocephalus should be the first intervention and in many cases may be the only surgical one. ${ }^{2,6,8,9,15,17}$ This is usually accomplished with either placement of VP CSF shunts or ETV, although there have also been reports in which aqueductoplasty has been described as another alternative. ${ }^{7}$ Other management procedures remain contro- 


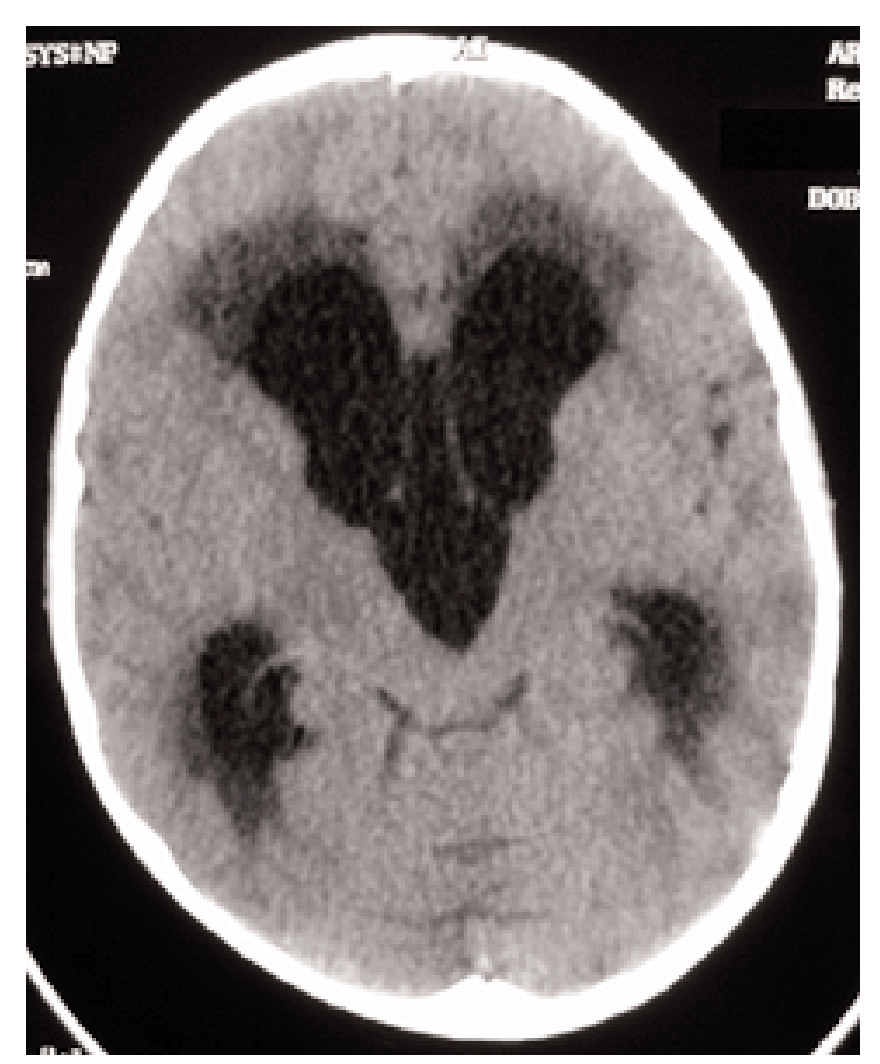

Fig. 1. Nonenhanced head CT scan obtained in an 8-year-old boy who presented with headaches and diplopia. The image demonstrates ventriculomegaly with transependymal edema.

versial. Although most tectal gliomas will follow an indolent course and will never need further interventions, a certain number will progress both clinically and radiographically..$^{15,16}$

It is believed that ETV provides a more physiological solution to hydrocephalus than shunt placement. ${ }^{10}$ In comments following the report of Wellons, et al., ${ }^{19}$ Ellenbogen alluded to a decrease in symptoms of intracranial hypotension with ETV when compared with VP CSF shunt placement. In fact, Pollack, et al., ${ }^{15}$ reported three cases of subdural hematomas after placement of VP shunts for hydrocephalus due to tectal glioma, and they discussed another patient with chronic low-pressure headaches. These complications have been noted infrequently after ETV. ${ }^{12}$ Furthermore, shunt placement procedures have the following known complications associated with them: shunt dependence, infection, mechanical failure, disconnection, and migration, to name a few ${ }^{4}$ whereas ETV can often be performed with minimal accompanying morbidity. ${ }^{10}$ Another advantage of ETV is the possibility of performing an endoscopic biopsy procedure at the time of ventriculostomy. ${ }^{11,14}$ Oka, et al.,${ }^{14}$ reported successful ETV and concomitant neuroendoscopic biopsy sampling of 11 tectal lesions, with partial resection of one lesion. Finally, Alkhani, et al., ${ }^{1}$ reported two interesting cases in which disappearance of enhancing tectal lesions was observed on serial imaging after successful ETV was performed.

Wellons, et al., ${ }^{19}$ recently described their results when using ETV exclusively in patients with tectal gliomas. Their

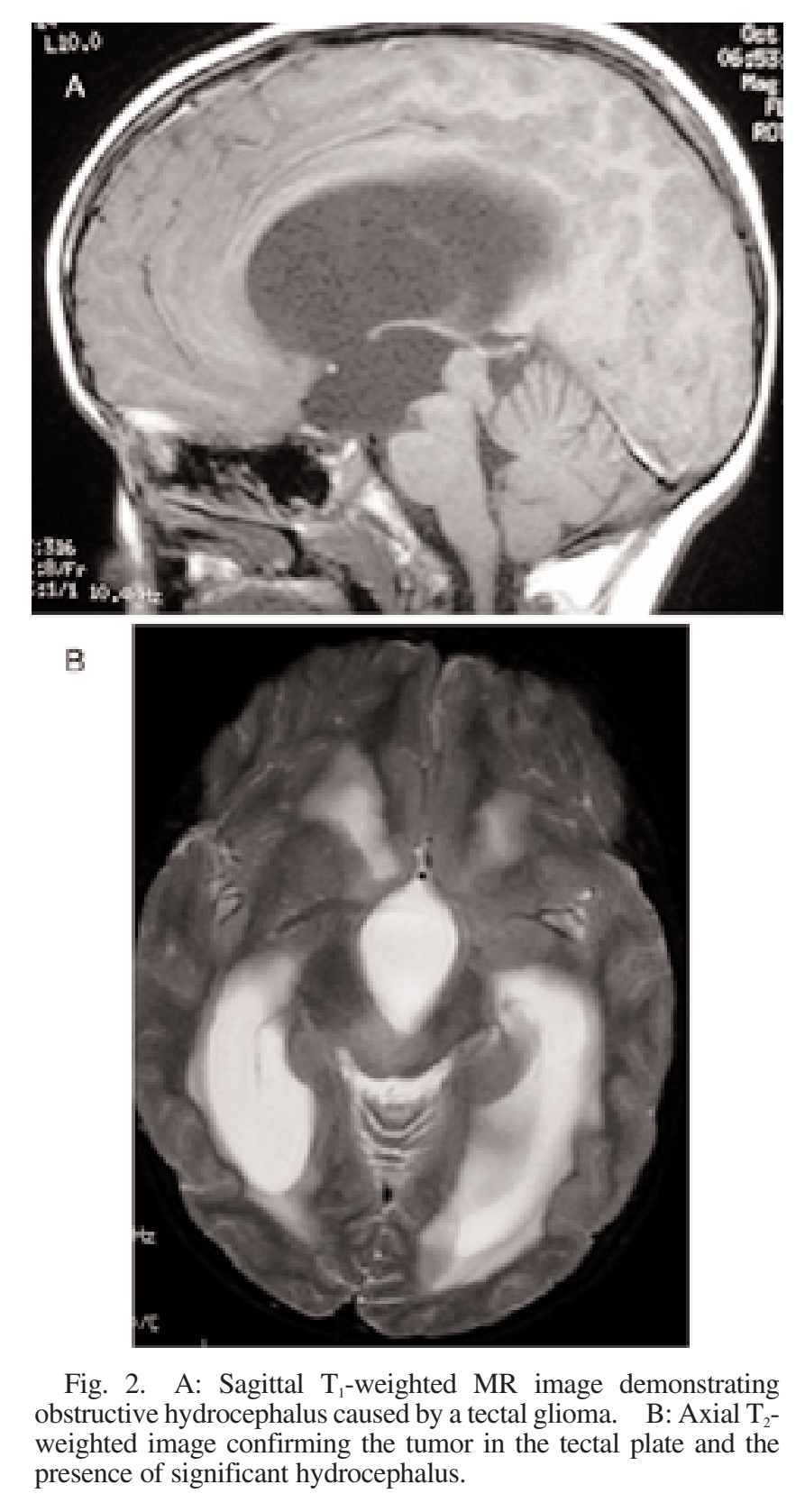

series included 13 children, all of whom remained shunt free at the time of follow-up evaluation, although two patients required revision ETV surgery. Javadpour and Mallucci11 also reported favorable results with ETV in 11 patients with tectal gliomas. Four patients required revision ETV, and two of the four eventually underwent shunt procedures. In these two studies, however, there was not a similar cohort of patients who underwent shunt placement with whom to contrast the results.

Our own series also demonstrates the success of ETV as the initial treatment for hydrocephalus caused by tectal gliomas. Patients who underwent ETV as their first procedure required far fewer additional CSF diversion procedures than those who received shunts initially. Our data also demonstrate that ETV can be successful even in patients in whom ventricular shunt placement has failed. We success- 

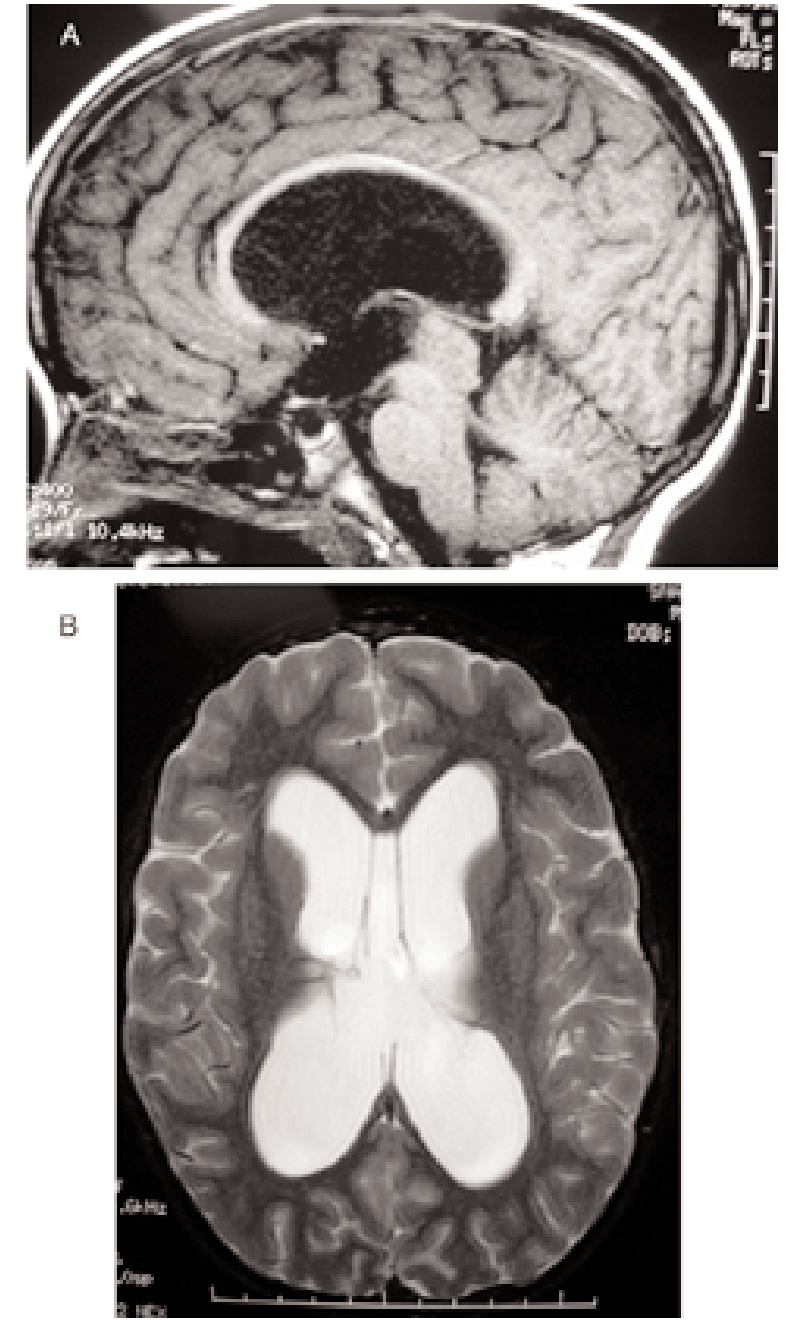

Fig. 3. Postoperative MR imaging studies obtained at the 6month follow-up visit after ETV. A: Sagittal $\mathrm{T}_{1}$-weighted MR image demonstrating a slight decrease in the ventricle size and stable appearance of the tectal glioma. B: Axial $\mathrm{T}_{2}$-weighted image confirming resolution of the transependymal edema and decrease in the ventricle size.

fully performed ETV in 10 such patients, and eight of them were shunt free at the time of follow up, although one required two procedures. Overall, the success rate of initial ETV was $88 \%$, and all eight patients remain shunt free. For the entire cohort of 18 patients who underwent ETV, the proportion who remained shunt free approached 90\%. Given the known malfunction and infection rates associated with VP collecting shunts ${ }^{4}$ and the success rates with ETV reported in our series and others, it seems clear that the procedure of choice for initial treatment of hydrocephalus associated with tectal gliomas is ETV.

\section{CONCLUSIONS}

Tectal gliomas are rare brain tumors that present in children or young adults with symptoms related to increased intracranial pressure secondary to obstructive hydrocephalus. The primary treatment for these patients is CSF diver- sion. We have found that ETV is more effective than ventricular shunt placement for hydrocephalus caused by tectal gliomas. We have also found that ETV can be performed with good success in patients in whom ventricular CSF shunting has failed.

\section{References}

1. Alkhani AM, Boop FA, Rutka JT: Involution of enhancing intrinsic tectal tumors after endoscopic third ventriculostomy: report of two cases. J Neurosurg 91:863-866, 1999

2. Antunes NL, Tavora L, Souweidane M: Globular glioma of the tectum. Pediatr Neurol 21:492-495, 1999

3. Barkovich AJ, Newton TH: MR of aqueductal stenosis: evidence of a broad spectrum of tectal distortion. AJNR 10:471-476, 1989

4. Blount JP, Campbell JA, Haines SJ: Complications in ventricular cerebrospinal fluid shunting. Neurosurg Clin N Am 4:633-656, 1993

5. Bognar L, Turjman F, Villanyi E, et al: Tectal plate gliomas. Part II: CT scans and MR imaging of tectal gliomas. Acta Neurochir 127:48-54, 1994

6. Bowers DC, Georgiades C, Aronson LJ, et al: Tectal gliomas: natural history of an indolent lesion in pediatric patients. Pediatr Neurosurg 32:24-29, 2000

7. Bulsara KR, Villavicencio AT, Shah AJ, et al: Successful aqueductal plasty and stenting for tectal plate tumor after failed third ventriculostomy: a case report. Surg Neurol 59:58-62, 2003

8. Daglioglu E, Cataltepe O, Akalan N: Tectal gliomas in children: the implications for natural history and management strategy. Pediatr Neurosurg 38:223-231, 2003

9. Grant GA, Avellino AM, Loeser JD, et al: Management of intrinsic gliomas of the tectal plate in children. A ten-year review. Pediatr Neurosurg 31:170-176, 1999

10. Hellwig D, Grotenhuis JA, Tirakotai W, et al: Endoscopic third ventriculostomy for obstructive hydrocephalus. Neurosurg Rev 28:1-38, 2005

11. Javadpour M, Mallucci C: The role of neuroendoscopy in the managment of tectal gliomas. Childs Nerv Syst 20:852-857, 2004

12. Kim BS, Jallo GI, Kothbauer K, et al: Chronic subdural hematoma as a complication of endoscopic third ventriculostomy. Surg Neurol 62:64-68, 2004

13. May PL, Blaser SI, Hoffman HJ, et al: Benign intrinsic tectal "tumors" in children. J Neurosurg 74:867-871, 1991

14. Oka K, Kin Y, Go Y, et al: Neuroendoscopic approach to tectal tumors: a consecutive series. J Neurosurg 91:964-970, 1999

15. Pollack IF, Pang D, Albright AL: The long-term outcome in children with late-onset aqueductal stenosis resulting from benign intrinsic tectal tumors. J Neurosurg 80:681-688, 1994

16. Poussaint TY, Kowal JR, Barnes PD, et al: Tectal tumors of childhood: Clinical and imaging follow-up. AJNR 19:977-983, 1998

17. Squires LA, Allen JC, Abbott R, et al: Focal tectal tumors: management and prognosis. Neurology 44:953-956, 1994

18. Vandertop WP, Hoffman HJ, Drake JM, et al: Focal midbrain tumors in children. Neurosurgery 31:186-194, 1992

19. Wellons JC III, Tubbs RS, Banks JT, et al: Long-term control of hydrocephalus via endoscopic third ventriculostomy in children with tectal plate gliomas. Neurosurgery 51:63-68, 2002

Manuscript received April 14, 2005.

Accepted in final form May 16, 2005.

Address reprint requests to: George I. Jallo, M.D., Division of Pediatric Neurosurgery, The Johns Hopkins Hospital, Harvey 811, 600 North Wolfe Street, Baltimore, Maryland 21287. email: gjallo1 @jhmi.edu. 